\title{
The Use of Adapted Educational Resources in the Teaching of Science and Biology in Classes that Include Visually Impaired Students
}

\author{
Claudio Cesar N. Felix ${ }^{1}$, Fernando B. Mainier ${ }^{2 *}$ \\ ${ }^{1}$ Colégio Pedro II, Rio de Janeiro, Brazil \\ ${ }^{2}$ Universidade Federal Fluminense, Niterói, RJ, Brazil
}

*Corresponding Author: Fernando B. Mainier, Universidade Federal Fluminense, Niterói, RJ, Brazil

\begin{abstract}
The article refers to a survey conducted with teachers of science and biology and the students of a school in Rio de Janeiro (Brazil), where there is mandatory inclusion of students with visual impairments in the regular classrooms of basic education. Semi-structured interviews and questionnaires were developed to meet as pedagogical support material and the teaching methodologies that integrate the classroom. The results highlighted that the formation of a collaborative network of the students without visual impairments in relation to those with impairments favours the learning and the awareness of the former about the inclusion, facilitating the dynamics in the classroom. From the valuation, it was clear that despite the insecurity on the part of the teachers, the various pedagogic resources adapted from traditional models or created by personal initiative have resulted in an integrated process of inclusion, still in improvement.
\end{abstract}

Keywords: Teachers of Science and Biology, Students with Visual Impairments, Pedagogic Resources, Education.

\section{INTRODUCTION}

The inclusion processes ranges from local and national educational projects to international policies. Since 1994, when at the World Conference on Special Needs Education held in Spain a document called the Salamanca Statement was prepared providing basic guidelines for the formulation and reform of educational policies and systems in line with the social inclusion movement, a worldwide trend has been consolidating: inclusive education has shown to be a process under construction. In it, professionalism mixes with improvisation and dedication related to overcoming obstacles, countering the discouragement and insecurity of those who are opposed to the whole process [1-3].

According to the Law for Guidelines and Bases of National Education in Brazil[4], the principle of education is the equality of conditions for access and permanence in the school, as well as the duty of the State to guarantee specialized and free care for students with disabilities, preferably in the regular network. Therefore, education systems must ensure educational methods, techniques and resources to meet their needs. It is the responsibility of the school manager to ensure compliance with these legal provisions.

In spite of the legal guidelines that bring to the table an increase in disabled students enrolled in regular education (Resolution CNE/CEB) [5], for Smeha and Ferreira [6], students with visual impairment or blindness mostly begin to study in common classrooms with unprepared teachers and are submitted to a lack of material and methodological options, in a process in which the personal creativity of teachers may or may not allow more meaningful learning. This is the challenge that should encourage in the education.

According to Vitaliano and Dall'acqua [7], the lack of specialized disciplines in teacher formation can be a gap in the inclusion process. This is a complex and highly important aspect in the effort for the effectiveness of inclusive schools. Still, by the authors argue there is a consensus that it is necessary to invest in teacher qualification so that inclusive models will be able to be developed in education. The process of inclusive education should be understood as an educational reform that, in order to take place, demands from teachers training based on teaching models different from the traditional ones [8]. 
As reported by Michels [9], changes have occurred with regard to teachers' qualification for inclusive education. The current reform envisages, in Resolution CNE/CEB No. 02/2001[5], that teachers working with students "with special educational needs" can follow two different models: the skilled or the specialized. According to this Resolution (Article 18):

- Trained teachers are considered to be those who work in common classes with students who present special educational needs. These teachers prove that their qualification, at the medium or higher level, included content about special education adequate to the development of skills and values to:

$>$ Realize the special educational needs of students and appreciate the inclusive education;

$>$ Be flexible the pedagogical action in the different areas of knowledge in an appropriate way to the special needs of learning;

$>$ Continuously evaluate the effectiveness of the educational process to meet special educational needs;

$>$ Work in teams that include teachers specializing in special education.

- Specialized teachers in special education are those who have developed competencies to identify special educational needs in order to define, implement, lead and support the implementation of flexibilization strategies, curriculum adaptation, pedagogical procedures and alternative practices adequate to the attendance of the same, as well as work with a team, assisting teachers from common classes with practices necessary to promote the inclusion of students with special educational needs.

- Teachers specializing in special education must prove:

$>$ Qualification in special education degree courses or in one of its areas, preferably concomitantly and associated with a degree for early childhood education or for the initial years of elementary education;

$>$ Complementation of studies or post-graduation in specific areas of special education, after graduation in the different areas of knowledge, for action on the final years of elementary and basic education.

- Teachers already working in the profession should be offered opportunities for continuing education, including at the level of specialization, by the educational institutions of the Union, the States, the Federal District and the Municipalities.

Therefore, in a legal way, the training of qualified teachers needs to be carried out linked to the offering of disciplines, or content, capable of addressing discussions about the education of students considered disabled. It is important to note that qualification should develop, with a view to professionalism, the skills to perform activities directly with disabled students, in addition to being able to work as part of a team. This demonstrates that these professionals should not plan the activities and dynamics to be developed with disabled students, leaving such responsibilities to the specialized teachers, but it seems that this is not always the case.

The present work does not aim to judge the teaching activities with the inclusion classes, but only to propose a diagnostic analysis to verify the use and the influence of the methods, techniques and educational resources adapted to the learning process of the students with some visual deficiency included in regular classes of the education system.

\section{Methodology}

In pursuit of the broader objective of analysing the use and influence of the methods, techniques and educational resources adapted to the learning process of students with some visual impairment included in regular classes of the educational system, the following actions were taken:

- Conducting semi-structured interviews with teachers of sciences and biology who work or worked in regular classes of Basic Education in which at least one visually impaired student was included.

- Application of a questionnaire for biology or sciences teachers who work with a visually impaired student enrolled in a regular high school class in the West Zone of Rio de Janeiro (Brazil). 
The choice of interviews as an initial preferential approach arises from Gray [10] because it was necessary to obtain very personalized data with opportunities to deepen the perspectives of the respondents. Initially, the research presents an exploratory profile involving the examination of teachers' feelings and attitudes towards the reality of the inclusion classes. Through the technique chosen for data collection, it was also possible to consider the nuances in the answers from which to adapt the questions or even improvise new ones.

In accordance with Gray[10], the use of a questionnaire is valuable because it allows a greater reliability of the data when is established to guarantee of anonymous answers. Through this method, in addition to optimizing opinions, it is possible to cover the research questions in terms of content and details.

\section{RESUltS AND DisCUSSION}

The questionnaires given to the teachers were composed of 13 questions, and a total of 22 teachers responded (all respondents sought participated), responsible for the disciplines of science and biology. Of all respondents, $31.8 \%$ were between the ages of 30 and 34 years, followed by $22.7 \%$ between 35 and 39 years. The remaining $45.5 \%$ were over 40 years of age. Of those participating, $45.5 \%$ have worked at the institution from 1 to 4 years, and $54.5 \%$ for more than 5 years.

When questioned about the effect that the presence of visually impaired students in their classes has on them, no one indicated fear or discouragement, and everyone admitted the feeling of determination and challenge. In addition, the willingness to work with visually impaired students was considered high by the majority.

In $100 \%$ of cases, teachers felt the need to use some pedagogic resource adapted for visually impaired students in their classes. Figure 1 illustrates the answers to this question.

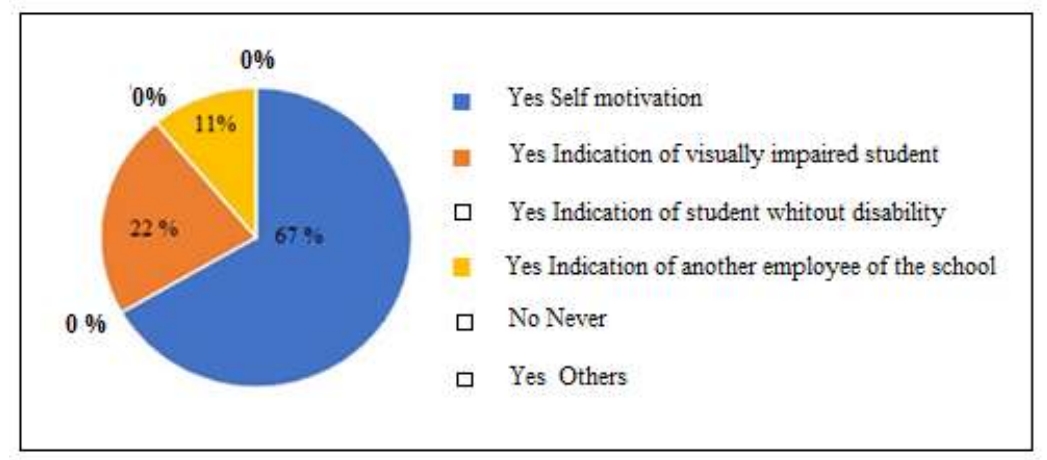

Figure1. Motivation to use any kind of adapted pedagogic resource as support for classes that include students with visual deficiencies. (Source: Survey data)

Of the 22 respondents, 14 use some adapted pedagogic resource made for visually impaired students during their classes in a regular network (Figure 2).

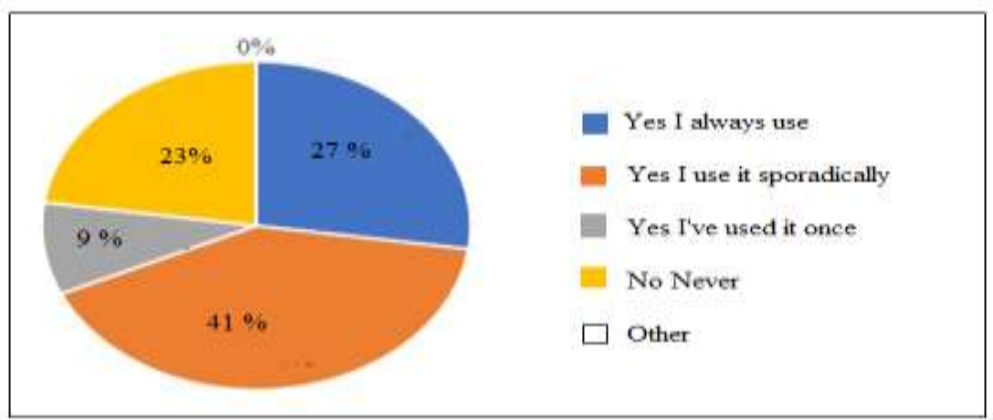

Figure2. Actual use of some adapted pedagogic resources directed to visually impaired students during classes (Source: Survey data)

In $100 \%$ of cases, teachers believed that it was necessary to use tactile material or other pedagogic resources adapted for visually impaired students. Many admit that this took place in both biology 
classes and those in other disciplines. In four cases, it was specified that the use of such material is necessary in disciplines that use many visual resources, such as images and graphics (biology, physics, chemistry, mathematics, drawing/art, physical geography).

When asked whether they consider themselves able to produce and/or use teaching resources adapted for the visually impaired, respondents were divided: 12 answered yes, while 10 responded no.

For positive responses, however, all considered that they were capable or, because they have had some experience, specifically focused on this differentiated teaching, or consider themselves capable but admit that specialized instruction is required for lesson planning. Negative responses focused on the justification for the absence of specific training/qualification/academic training for this purpose.

All participating teachers believed that changes were needed in the teaching methods adopted in the classroom regarding the adaptation of pedagogic resource directed to visually impaired students. The suggested changes were:

- Partnership with another teaching professional during class.

- Lower number of students per class than practiced.

- Adoption of tactile resources as models low and high relief to adapt the visual demands of the discipline, in addition to audio resources.

- Insertion of students with normal vision in the process of learning for visually impaired students.

- Conduct refresher courses that can offer training or suggestions for the teacher to act appropriately in classes that contain students with and without visual impairments.

- Creation and of a sector or specialized group for the production of three-dimensional models and other adapted pedagogic resources directed to visually impaired students. Figure 3 shows the types of adapted pedagogic resources used.

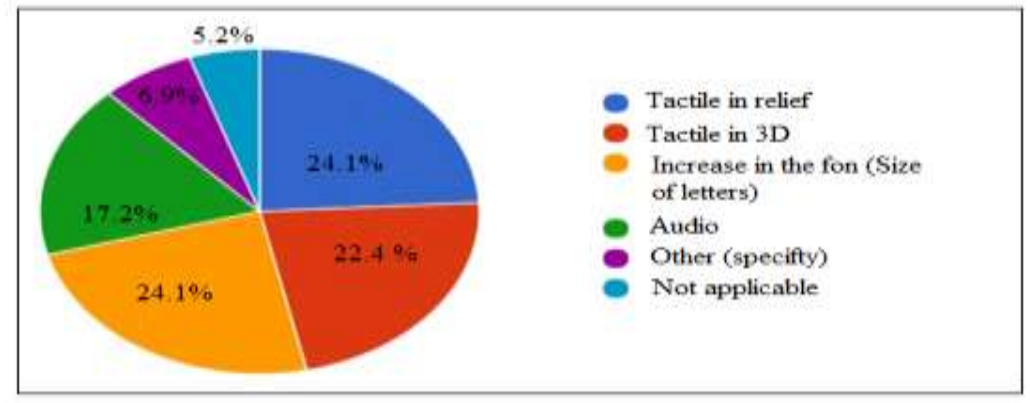

Figure3. Adapted teaching resources and the percentage of their use. (Source: Survey data)

Resources marked as "other" were specified as follows:

- Digital images with specific contrasts.

- Approach of topics in practical classes.

- "Universal design" pedagogic game (for everyone, regardless of visual condition), colourful and expanded schemes for students with low vision, coloured blocks.

- Text translated into Braille.

The materials noted by the respondents as more suitable for the adapted resources were plastic, Styrofoam (polystyrene), tracing paper, sandpaper, relief adhesive and string.

The criteria for their use are the ease of handling, low cost and practicality. In general, materials that have different textures are used, being adapted to each situation.

In almost all cases ( 21 respondents),the respondents themselves prepared the adapted material. In a few cases, it was prepared by trainees ( 3 respondents), provided by the school (6 respondents) or provided by a university/institute (4 respondents). In only one case, the material was provided by the visually impaired student himself. 
In 14 of the cases in which the teachers produced the resources, on their own initiative. In one case, there was assistance from Centre of Attention to People with Specific Needs (CAPSN) teachers. Only one other teacher claimed to have taken a course in producing teaching materials at the Benjamin Constant Institute (BCI).Only in a third case did the respondent state that validation of materials is done with the visually impaired students themselves. Before being extensively handled, they are tested by these (target audience) for the assessment of their suitability.In other cases where there was a positive response to having an orientation, it was indicated as not being formal, having been conducted by personal motivation surveys on the Internet or by talking with other teachers who had similar experiences.

The elaboration of the adapted resource is given in Figure 4.

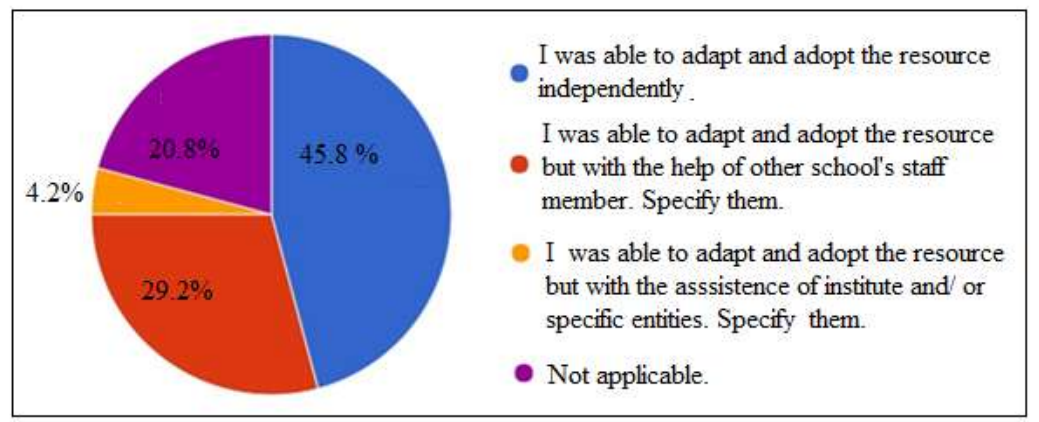

Figure4. How adaptation of pedagogic resources was elaborated. (Source: Survey data)

No respondent stated that he or she could not adapt or adopt them in the classroom.

The help indicated by the teachers was the exchange of information with other teachers, or with CAPSN professionals. On three occasions, respondents admitted that despite adopting the resource independently, it was not easy, and they spent hours of extra work on it doing a great deal of reading, research, modification and adaptation.

Among the teachers who used an adapted resource in the classroom, there were 15 cases in which the material was purchased with the teacher's own funds, only one case in which it was purchased by the school/laboratory, and 5 cases in which it was provided by the school.

When asked if it has been possible to reconcile the optimization of the class in a regular space with visually impaired students, the respondents answered as shown in Figure 5.

Those who answered "never" explained that there is a great demand by visually impaired students for the use of tactile materials, so they can identify and understand much of the given matter.In addition, they pointed out the use of diagrams and graphs that are widely used in classrooms, as well as the difficulty in getting sighted students to contribute to the learning of the blind students, since the conversation ends up hindering much the focus of the blind.

Those who answered "almost never" admitted that there is still great difficulty with insertion of the visually impaired students, even more when teaching without the aid of a monitor, and point to the loss of rhythm and lack of interest that can occur for the sighted students.

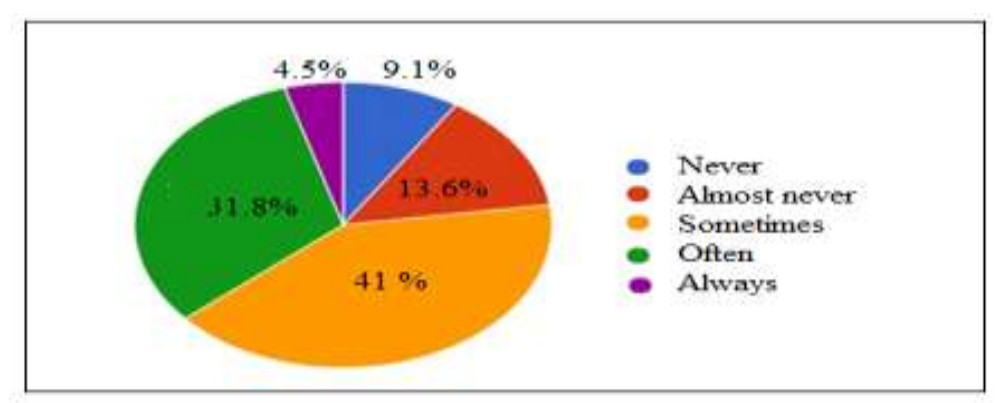

Figure5. Respondents' opinions about the optimization of classes that include visually impaired students. (Source: Survey data) 
Teachers who answered "sometimes" also pointed to the fact that "there are some topics that rely heavily on visualization which for the blind need to be carefully described, which gets tiring and repetitive for those with normal vision". Once again, this highlights the lack of material and human support in the classroom as well the fact that the contribution of sighted students greatly influences the development of the lesson.

For those who responded "almost always", there are few effective justifications, but they also noted the limitations and difficulties described above.

The one teacher who answered "always" stated that "the use of the resource does not only favour the visually impaired, it reinforces the learning of all".

Finally, Figure 6 shows the replies when the teachers were asked about the assimilation of learning when students with visual impairment are included in the regular teaching spaces.

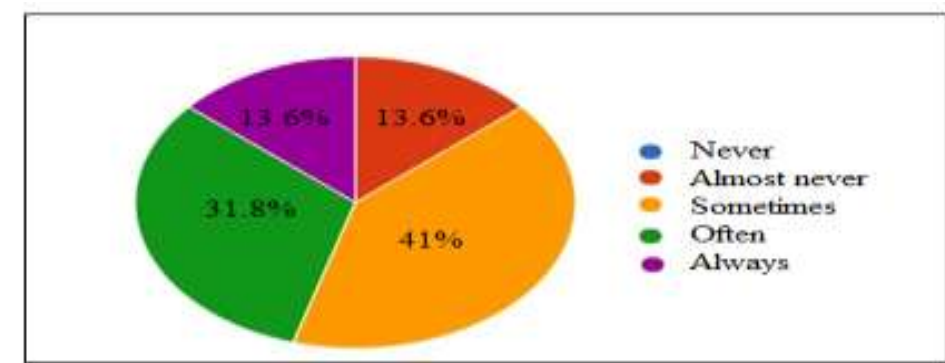

Figure6. Respondents' comments about the assimilation of knowledge by the visually impaired in the classroom in regular classes. (Source: Survey data)

It is clear that the formation of a collaborative network of sighted students in relation to those who are visually impaired contributes to the learning of the latter and to an awareness of the former about inclusion, facilitating the dynamics in the classroom. Practically all the teachers at one time or another occasion of research done defended this proposition.

In addition, there was a case in which the teacher admitted that "the teacher of the regular class does not alwaysassimilated visually impaired students and therefore does not produce/think up materials for them. In fact, the teachers think that the student is the responsibility of the Specialized Educational Assistance (SEA) teacher; therefore, that is where their learning should occur.'This demonstrates that it is clearly necessary to immerse the teacher in the learning of the visually impaired student.

On the other hand, one of the teachers who answered "sometimes" to the question stated the following:

The inclusion of visually impaired students depends on adapted resources but also requires specific methodologies as well as the involvement of all sectors of the school community. Including presupposes inclusive actions in the collective. Consequently, the assimilation of knowledge in classes with included students requires coordinated actions that do not end with a specific classroom, technique or resource.

\section{CONClusions}

The answers obtained from the questionnaire bring in their totality the perception of the need to use resources adapted for the teaching of science and biology to visually impaired students and show that in most cases, the initiative to make the material comes from the professional themselves.

In the teachers' responses, there is also an equal partition on an individual capacity for the production of adapted material. According to Brumeret al. [11], inclusion by the educational path of visually impaired students should not occur as a charitable activity, but rather should demonstrate a new face of education in which inclusion should allow the rescue of the blind students 'citizenship, a position shared by the responding teachers. The problems here are related to the allocation of resources, lack of qualified professionals and lack of pedagogic resources necessary to respond to such demand.

Regarding the allocation of resources, the solution involves policies and other variables not related to the pedagogical sphere, but the suggestions related to resources of adapted materials point to a more participatory action of sighted students and the organization of a specialized sector in creating, 
inventorying and disseminating pedagogic materials adapted for the visually impaired.

Finally, the research explained that the formation of a collaborative network with the participation of both sighted students and the visually impaired allows a better fit for the inclusion process, minimizing the tedious and repetitive video descriptions of content-dependent topics of visualization.

\section{REFERENCES}

[1] Avramidis, E., and Kalyva, E. (2007), The influence of teaching experience and professional development on Greek teachers' attitudes towards inclusion. European Journal of Special Needs Education, 22(4), 367389.

[2] Avramidis, E., and Norwich, B. (2002), Teachers' attitudes towards integration/inclusion: a review of the literature. European Journal of Special Needs Education, 17(2), 129-147.

[3] Kumar, D., Ramasamy, R.,and Stefanich, G. P. (2001), Science for students with visual impairments: teaching suggestions and policy implications for secondary educators. Electronic Journal of Science Education, 5(3), 4p.

[4] Lei $n^{\circ}$ 9394/96 de Diretrizes e Bases da Educação Nacional (Law n ${ }^{\circ}$ 9394/96 Guidelines and Bases for National Education), (1996), Ministério da Educação e do Desporto. Brasília, Brazil, (in Portuguese).

[5] Resolução CNE/CEB No 2,11/09/2001, Diretrizes Nacionais para a Educação Especial na Educação Básica(Resolution CNE/CEB No. 2, 11/09/2001, National guidelines for special education in basic education), http://portal.mec.gov.br/cne/arquivos/pdf/CEB0201.pdf (in Portuguese).

[6] Smeha, L. N. and Ferreira, I. V. (2008), Prazer e sofrimento docente nos processos de inclusão escolar (Pleasure and suffering teaching in school inclusion), Revista Educação Especial, 21(31). (in Portuguese).

[7] Vitaliano, C. R. and Dall'acqua, M. J. C.( 2012), Análise das diretrizes curriculares dos cursos de licenciatura em relação à formação de professores para inclusão de alunos com necessidades especiais (Analysis of the curriculum guidelines of the graduate courses in relation to teacher training for inclusion of students with special needs), Teias, 103-121.(in Portuguese).

[8] Rodrigues, D. and Lima-Rodrigues, L. (2011), Formação de Professores e Inclusão: como se reformam os reformadores?(Teacher education and inclusion: how to retire the reformers?), Educar em Revista, n. 41.(in Portuguese).

[9] Michels, M. H. (2006), Gestão, formação docente e inclusão: eixos da reforma educacional brasileira que atribuem contornos à organização escolar (Management, teacher education and inclusion: Brazilian educational reform shafts which attach contours to the school organization), Revista Brasileira de Educação, 11(33), 406-423. (in Portuguese).

[10] Gray, D. E. (2016), Pesquisa no mundo real (Research in the real world), Porto Alegre, Brazil, Editora Penso. (in Portuguese).

[11] Brumer, A., Pavei,K., and Mocelin, D. G. (2004), Saindo da "escuridão": perspectivas da inclusão social, econômica, cultural e política dos portadores de deficiência visual em Porto Alegre (Coming out of the "darkness": perspectives of social inclusion, economic, cultural and policy of the visually impaired in Porto Alegre), Sociologias, 6(11), 300-327. (in Portuguese).

Citation: Claudio C.N. Felix and Fernando B. Mainier " The Use of Adapted Educational Resources in the Teaching of Science and Biology in Classes that Include Visually Impaired Students" International Journal of Humanities Social Sciences and Education (IJHSSE), vol 5, no. 1, 2018, pp. 98-104. doi: http://dx.doi.org/10.20431/2349-0381.0501015.

Copyright: () 2018 Authors. This is an open-access article distributed under the terms of the Creative Commons Attribution License, which permits unrestricted use, distribution, and reproduction in any medium, provided the original author and source are credited. 